\title{
LAJU TANGKAP, SEBARAN DAERAH PENANGKAPAN DAN POTENSI STOK SUMBER DAYA IKAN TUNA CAKALANG TONGKOL (TCT) DI SUMATERA UTARA
}

\section{CATCH PER UNIT EFFORT, DISTRIBUTION OF FISHING GROUND AND POTENTIAL STOCK OF TUNA CAKALANG TONGKOL (TCT) IN NORTH SUMATERA}

\author{
Gussasta L. Arnenda*, Bram Setyadji, dan Zulkarnaen Fahmi \\ Loka Riset Perikanan Tuna \\ Jl. Mertasari No. 140 Br Suwung Kangin, Sidakarya, Denpasar, Bali \\ E-mail: gussastaarnenda@gmail.com
}

(Diterima: 9 Februari 2021; Diterima setelah perbaikan: 29 September 2021; Disetujui: 29 September 2021)

\begin{abstract}
ABSTRAK
Potensi sumber daya perikanan tuna cakalang tongkol (TCT) di Wilayah Pengelolaan Perikanan (WPP-NRI) 572 sanagt tinggi. Salah satu wilayah perikanan di Indonesia penghasil utama komoditas ini adalah Sumatera Utara. Tujuan penelitian ini adalah untuk menganalisis laju tangkap, daerah sebaran hasil tangkapan TCT peralat tangkap di Sumatera Utara, serta kontribusinya terhadap WPP 572 dan Nasional. Penelitian ini dilaksanakan dari Januari hingga Desember 2019. Pengambilan data dilakukan secara langsung dilokasi penelitian dengan metode stratifield random sampling. Data daerah penangkapan diperoleh dari logbook penangkapan ikan yang berasal dari PSDKP PPN Sibolga dan data dari Dinas Perikanan Provinsi Sumatera Utara. Daerah penangkapan dibuat menggunakan aplikasi Q-GIS. Nilai CPUE tertinggi pada pukat cincin sebesar 10,45 ton/trip, dan terendah jaring insang sebesar 0,001 ton/trip. Nilai laju tangkap tertinggi bulan oktober sebesar 20,63 ton/trip dan terendah Agustus sebesar 9,31 ton/trip. Pendaratan hasil tangkapan lebih banyak di tangkahan. Sebaran daerah penangkapan pukat cincin dari $6^{\circ}$ $\mathrm{LU}-6^{\circ} \mathrm{LS}$ dan $85^{\circ} \mathrm{BT}-101^{\circ} \mathrm{BT}$, pancing ulur dari $4^{\circ} \mathrm{LU}-2^{\circ} \mathrm{LS}$ dan $92^{\circ} \mathrm{BT}-99^{\circ} \mathrm{BT}$, dan bagan dari $3^{\circ} \mathrm{LU}$ - $2^{\circ}$ LS dan $98^{\circ}$ BT - $99^{\circ}$ BT. Kontribusi TCT di Sumatera utara tertinggi cakalang, terendah Tongkol Komo. Kontribusi TCT Terhadap WPP 572 besar akan tetapi terhadap nasional sedikit. Hasil tangkapan TCT di lebih banyak tertangkap di ZEE, dan Teritorial dari pada di laut lepas.
\end{abstract}

KATA KUNCI: daerah penangkapan, stok, Sumatera Utara, TCT

\begin{abstract}
The potential of skipjack tuna and little tuna (TCT) in the Fisheries Management Area (FMA) 572 is very high. One of the fishery areas in Indonesia that is the main producer of this commodity is North Sumatra. The purpose of this study was to analyze the catch rate, the distribution area of the catch of TCT fishing gear in North Sumatra, as well as its contribution to WPP 572 and the National. This research was conducted from January to December 2019. Data collection was carried out directly at the research location using themethod stratifield random sampling. Data on fishingobtained from grounds werelogbooks fishingfrom PSDKP PPN Sibolga and data from the Fisheries Service of North Sumatra Province. The fishing area was created using the Q-GIS application. The highest CPUE value in ring seines was 10.45 tons/trip, and the lowest was 0.001 tons/trip for gill nets. The highest catch rate in October was 20.63 tons/trip and the lowest in August was 9.31 tons/trip. Landing catches more in the hands. The distribution of ring trawl fishing area is from $6^{\circ}$ North Latitude - 6 South Latitude and 85 East Longitude - $101^{\circ}$ East Longitude, hand line from 4 North Latitude - 2 South Latitude and 92 East Longitude - $99^{\circ}$ East Longitude, and the chart is from 3 North Latitude - 2 South Latitude and 98 East Longitude - 99 East Longitude. The highest TCT
\end{abstract}

\# Korespondensi: Loka Riset Perikanan Tuna

E-mail: gussastaarnenda@gmail.com 
contribution in North Sumatra was skipjack tuna, the lowest was Tongkol Komo. The contribution of TCT to FMA 572 is large but to the national level it is small. More TCT catches are caught in the EEZ and Territorial than in the high seas.

KEYWORDS: Wood; smoking; pangasius; quality

\section{PENDAHULUAN}

Sumber daya Ikan yang memiliki potensi besar di Indonesia adalah perikanan Tuna, Cakalang, dan Tongkol (TCT) (Firdaus, 2019). TCT juga merupakan komoditas perikanan yang memiliki nilai komersial tinggi (Sulistyaningsih, Barata and Siregar, 2011). Stok sumber daya ikan tuna dan cakalang selama periode 1992-2015 mengalami deplesi negative dengan penurunan sebesar 2.828 ton per tahun dengan nilai potensi kerugian atau kehilangan akibat penurunan stok yang mencapai Rp131,89 miliar per tahun (Firdaus, 2019). Total produksi tuna di Samudra Hindia pada tahun 2017 sebesar 552.409 ton, sedangkan produksi cakalang sebesar 524.282 ton dan kelompok ikan tongkol meliputi tongkol lisong (Auxis rocher), tongkol krai (Auxis thazard) dan kawakawa (Euthynnus affinis) sebesar 245.532 ton (IOTC, 2018). Status stok ikan tuna mata besar, albakor, cakalang dan neritik tuna (tongkol komo) masih berada dalam zona hijau atau dalam arti belum terjadi overfishing sedangkan untuk tuna sirip kuning sudah berada pada zona merah yang berarti sudah terjadi lebih tangkap atau overfishing (IOTC, 2019).

Daerah penangkapan secara spasial diperlukan agar pelaku perikanan dapat melakukan pengelolaan dengan benar (Tangke, 2014). Penangkapan pada daerah penangkapan potensial harus dikelola menggunakan jenis-jenis alat tangkap yang sesuai dengan jenis ikannya (Hidayat, Noegroho and Wagiyo, 2017). Keragaman armada penangkap ikan dan alat tangkap juga mempengaruhi tingkat eksploitasi ikan di suatu perairan (Arnenda and Rochman, 2019). Sehinga nilai produksi dan CPUE dari masing-masing alat tangkap sangat penting untuk mendukung pengelolaan perikanan yang bertanggung jawab (Nugroho and Jatmiko, 2019).

Sumatera Utara dalam melakukan aktivitas pendaratan ikan memiliki Pelabuhan Perikanan Nusantara Sibolga sebagai pelabuhan utama, dan tangkahan yang dikelola oleh pihak swasta secara perorangan atau kelompok (Simatupang and Lubis, 2012). Potensi sumberdaya ikan pelagis besar di perairan Sibolga sangat tinggi dan produktivitas penangkapan sangat potensial (Limbong, 2019). Pelabuhan Perikanan Nusantara Sibolga merupakan basis pendaratan armada perikanan tuna di Samudera Hindia barat Sumatera (Wijopriyono, 2012).
Tujuan peneliitian ini adalah unutk mengetahui tentang perkembangan terkini potensi stok sumber daya ikan Tuna, Cakalang dan Tongkol (TCT) dan sebaran darah penangkapan secara spasial di Sumatera Utara sangat berguna untuk memberikan masukan bagi pengembangan usaha penangkapan maupun manajemen pengelolaan sumberdaya ikan secara tepat dan berkesinambungan, khususnya di Samudra Hindia (WPP RI 572).

\section{BAHAN DAN METODE}

Penelitian dilakukan melalui kegiatan survey secara langsung di Pelabuhan Perikanan Nusantara Sibolga, Tangkahan di Sibolga dan Tapanuli Tengah, serta seluruh dinas perikanan di Sumatera Utara (Sumut). Data primer (biologi dan produksi) diperoleh secara langsung dengan pelaku perikanan terkait dan pengukuran langsung di lapangan dengan metode stratifield random sampling. Data sekunder (lokasi daerah penangkapan dan data statistik perikanan tangkap TCT) berasal dari data statistik di PPN Sibolga dan data dari dinas provinsi Sumatera Utara. Data daerah penangkapan TCT diperoleh berdasarkan atas catatan harian e-logbook sejumlah kapal yang menggunakan VMS dengan berbagai alat tangkap yang berbasis di PPN Sibolga. Data produksi diperoleh dari data statistik di PPN Sibolga, dan data SL3 dari PSDKP di PPN Sibolga. Pengolahan data meliputi hasil tangkapan harian meliputi jumlah dan jenis tangkapan, data upaya penangkapan (nama kapal, ukuran kapal, jumlah trip, jumlah setting alat tangkap), jenis alat tangkap daerah pengkapan dan informasi aspek operasional penangkapan lainnya. Lokasi Penelitian bisa dilihat pada Gambar 1.

Hasil tangkapan per upaya penangkapan (catch per unit of effort atau CPUE) jenis ikan TCT dihitung dengan menggunakan rumus sebagai berikut :

CPUE $=$ Total Tangkapan / Jumlah Trip

Sebaran daerah penangkapan dipetakan dengan mengunakan aplikasi QGIS 3.4, dipetakan sebaran hasil tangkapan secara spasial perspesies kemudian peralat tangkap. Penghitungan kontribusi terhadap hasil tangkapan nasional dilakukan perbandingan data hasil produksi di Sumatera Utara dengan data statistik nasional tahun 2018. Penghitung data produksi di dalam dan di luar ZEE, dihitung secara manual setelah dilakukan pemetaan dengan skala $1 \times 1$. 


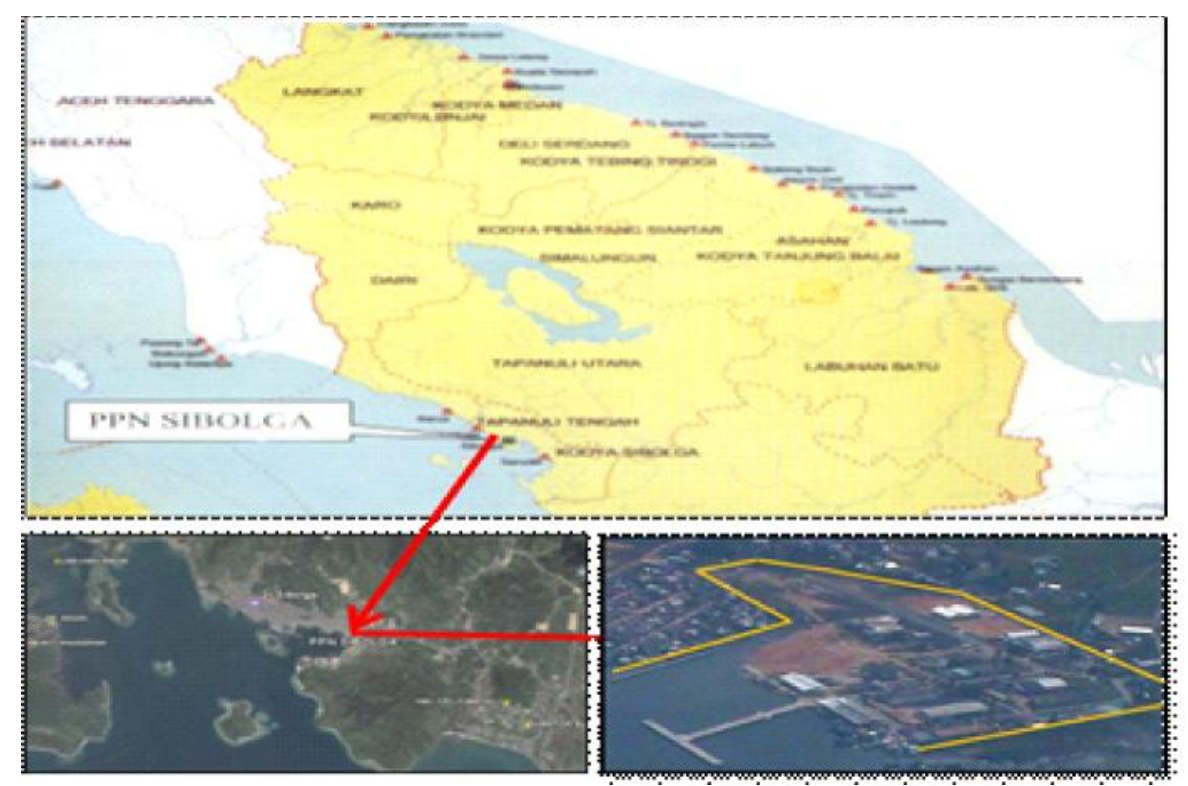

Sumber: PPN Sibolga, 2018

Gambar 1. Lokasi Penelitian di Sumatera Utara dan letak PPN Sibolga.

Figure 1. Research locations in North Sumatra and the location of PPN Sibolga.

\section{HASIL DAN BAHASAN}

\section{a. Laju Tangkap/CPUE}

Laju tangkap tahunan untuk produksi TCT berdasarkan data Statistik PPN Sibolga, menunjukkan tren kenaikan CPUE untuk pukat cincin mulai 2014 2018 . Nilai CPUE tertinggi pukat cincin pada 2018 sebesar 10,45 ton/trip. Nilai CPUE terendah pada armada jaring insang sebesar 0,001 ton/trip pada 2018. Alat tangkap dominan di PPN Sibolga adalah pukat cincin. Tren bulanan laju tangkap ikan untuk armada pukat cincin pada tahun 2018, menunjukkan kenaikan mulai bulan September sampai Oktober. Nilai laju tangkap tertinggi terjadi pada bulan oktober sebesar 20,63 ton/trip dan terendah bulan Agustus sebesar 9,31 ton/trip. Tren laju tangkap TCT (madidihang, cakalang, tongkol komo, tongkol krai) pada pukat cincin dalam 5 tahun terakhir. Produksi TCT pada tahun 2018 didominasi oleh cakalang sebesar 15.352,40 ton, diikuti madidihang $2.524,42$ ton, tongkol krai $1.956,60$ ton dan tongkol komo 40,4 ton. Tren produksi cakalang mengalami kenaikan dalam 5 tahun terakhir dibandingkan jenis tongkol dan tuna madidihang. Kapal penangkap ikan TCT yang berbasis di PPN Sibolga cukup beragam, antara lain pukat cincin, bagan perahu, jaring insang dan pancing. Hasil
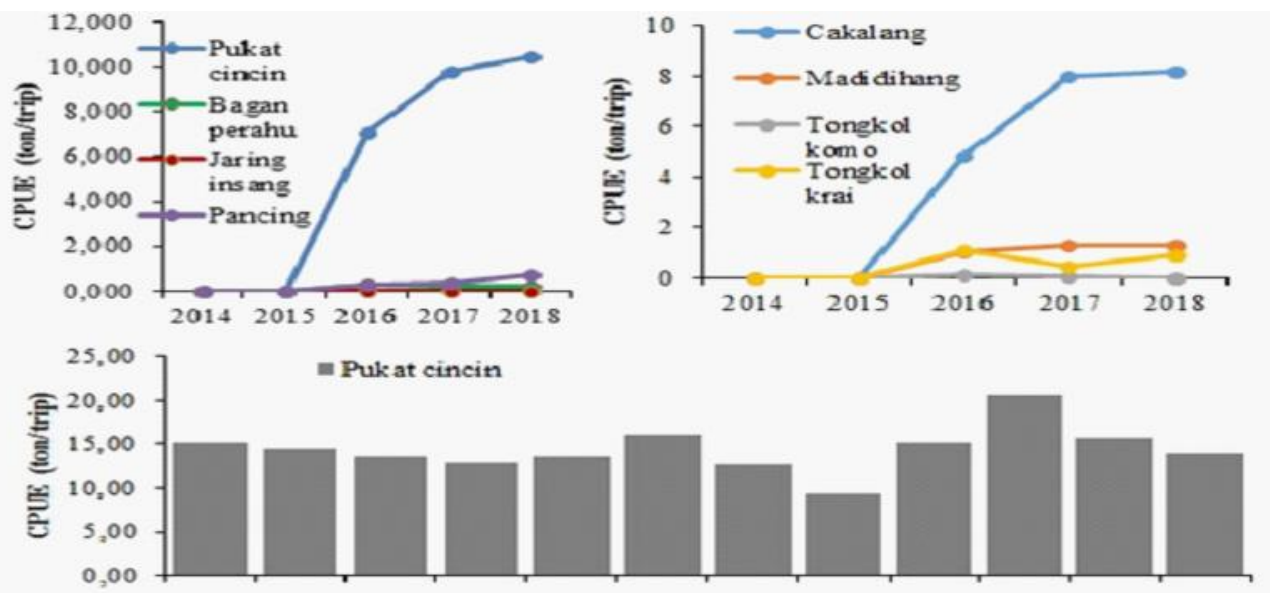

Sumber: Data Statistik PPN Sibolga

Gambar 2. Tren laju tangkap (CPUE).

Figure 2. Catch Per Unit Effort (CPUE). 
tren CPUE di sumatera utara cenderung mengalami kenaikan dan di dominasi oleh pukat cincin. Sumberdaya ikan pelagis di daerah penangkapan kapalkapal pukat cincin telah menunjukkan gejala yang sangat memprihatinkan atau dapat dikatakan telah terjadi overfishing (Wurlianty, Wenno and Kayadoe, 2015). Peningkatan CPUE ini diduga karena perikanan purse seine semi industri memiliki hak mengeksploitasi sumber daya ikan di beberapa wilayah pengelolaan perikanan, yaitu: WPP 771 (Laut China Selatan), WPP 772 (Laut Jawa), WPP 773 (Selat Makassar dan Laut Flores), WPP 572 (Samudera Hindia Barat Sumatera), WPP 573 (Samudera Hindia Selatan Jawa) dan KTI terdiri dari WPP 715 (Laut Seram - Teluk Tomini) dan WPP 716 (Laut Sulawesi) begitu juga tempat pendaratan hasil tangkapan memungkinan dapat singgah lebih dari satu pelabuhan pendaratan singgah (Atmaja, Natsir and Sadhotomo, 2012). Hasil penelitian ini berbeda dengan keadaan CPUE di Aceh yang mengalami penurunan sebesar $13,4 \%$ pertahun (Salmarika, Tauruman and Wisudo, 2019).

\section{b. Produksi TCT Dominan}

Produksi ikan di PPN Sibolga dan tangkahan pada tahun 2018 sebanyak 30.044 ton dan produksi ikan selama tahun 2017 sebanyak 22.933 ton yang berarti mengalami peningkatan produksi 7.111 ton atau 31,01
\% dari tahun 2017 (PPN Sibolga, 2018). Keberadaan tangkahan di Sibolga terhadap pendaratan hasil tangkapan di PPN Sibolga berpengaruh cukup besar setiap tahunnya. Jumlah tangkahan yang tersebar di Kota Sibolga sebanyak 29 unit dan Tapanuli Tengah sebanyak 7 unit pada tahun 2018. Rata-rata selisih hasil tangkapan yang didaratkan di kedua tempat tersebut adalah $15.153,3$ ton per tahun dan selisih terbesar terjadi pada tahun 2018 yakni 21.525 ton. Dengan demikian, pendaratan hasil tangkapan lebih cenderung dilakukan di tangkahan-tangkahan dari pada ke PPN Sibolga. Produksi TCT pada tahun 2018 didominasi oleh cakalang sebesar 15.352,40 ton, diikuti madidihang 2.524,42 ton, tongkol krai $1.956,60$ ton dan tongkol komo 40,4 ton. Tren produksi cakalang mengalami kenaikan dalam 5 tahun terakhir dibandingkan jenis tongkol dan tuna madidihang. Dalam 5 tahun terakhir (2014 - 2018), kapal pukat cincin mendominasi hasil tangkapan TCT sebesar 91,39\%, diikuti kapal bagan perahu 7,31\%, kapal pancing 1,04\% dan kapal jaring insang 0,09\% .Produksi rata-rata TCT yang didaratkan di Pelabuhan dalam 5 tahun terakhir adalah 5.886 ton, sedangkan yang didaratkan di Tangkahan sebesar 10.893,72 ton. Produksi cakalang yang didaratkan di Pelabuhan sebesar $28,4 \%$, sedangkan yang didaratkan di Tangkahan sebesar 71,6\% (Gambar 3).
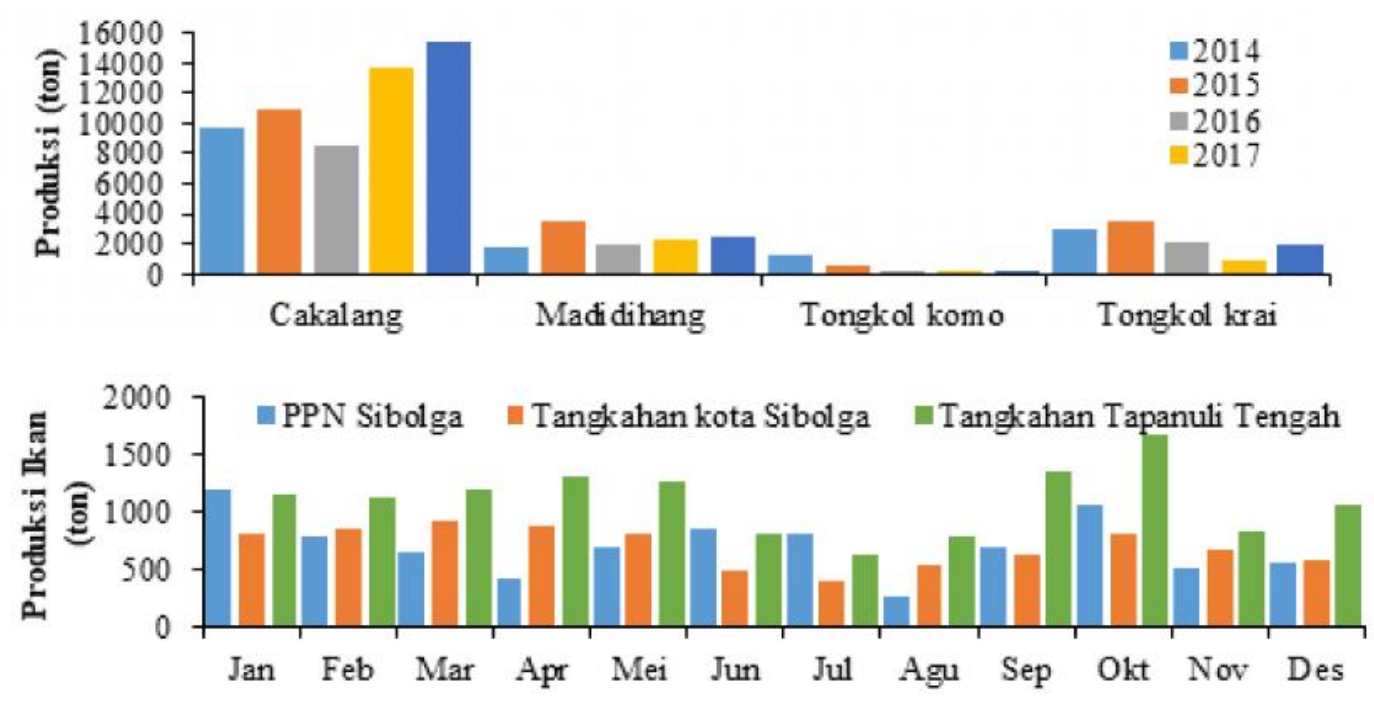

Sumber: Data Statistik PPN Sibolga

Gambar 3. Produksi TCT di PPN Sibolga dan Tangkahan.

Figure 3. Production of TCT at PPN Sibolga and Non-PPN.

Hasil penelitian sumber daya cakalang dan madidihang mendominasi hasil tangkapan WPP 572 . Proporsi cakalang dan madidihang mencapai 95\% di WPPNRI 572 dan 66\% di WPPNRI 573 dengan dominasi ikan yang tertangkap adalah ikan yang belum matang gonad (Jatmiko, Catur and Fahmi, 2020). Tangkapan pancing tidak mendominasi di Sumater Utara yang berkebalikan dengan kondisi alat penangkapan ikan yang digunakan di PPP Pondokdadap, Sendang Biru tercatat sebanyak $70,42 \%$, sedangkan pukat cincin sebanyak 9,82\% dan pancing rawai sebanyak 19,76\%, namun dominasi hasil terbanyak adalah cakalang dan 
juwana tuna (Agustina, Jatmiko and Sulistyaningsih, 2020). Sehingga dapat disimpulkan bahwa TCT merupakan hasil tangkapan utama di wilayah Samudera Hindia.

\section{c. Kontribusi produksi TCT Pelabuhan terhadap total produksi TCT di WPP 572 dan Nasional}

Cakalang mempunyai kontribusi terbesar terhadap total produksi TCT di WPP 572 pada tahun 2018 yaitu sebesar $49.95 \%$ atau setara dengan 15.352 ton. Kontribusi terkecil adalah tongkol komo pada tahun 2018 sebesar $0.24 \%$. Cakalang mempunyai kontribusi terbesar terhadap total produksi TCT di WPP 572 pada tahun 2018 yaitu sebesar $3.48 \%$ atau setara dengan
15.352 ton. Kontribusi terkecil adalah tongkol komo pada tahun 2018 sebesar $0.02 \%$. (Tabel 1 dan 2)

\section{d. Hasil tangkapan TCT di dalam ZEE dan di luar ZEE.}

Produksi Tuna, Cakalang dan Tongkol (TCT) sangat mendominasi hasil tangkapan secara keseluruhan. Produksi TCT di WPP RI 572 di PPS Sibolga pada tahun 2018 menurut logbook tahun 2018, cakalang mendominasi dengan hasil tangkapan sebnyak $10.194,406$ ton. Total tangkapan keseluruhan mencapai $13.433,369$ ton. Produksi TCT di laut lepas mencapai $1.432,74$ ton, sedangkan produksi teritorial $1.414,882$ ton, dan ZEE mencapai $10.585,747$ ton. (Tabel 3)

Tabel 1. Kontribusi produksi TCT per spesies yang didaratkan di PPN Sibolga terhadap total produksi TCT di WPP 572 tahun 2016

Table 1. Contribution of TCT production per species landed in PPN Sibolga to total TCT production in FMA 572 in 2016

\begin{tabular}{|c|c|c|c|c|c|c|c|c|c|c|c|}
\hline \multirow{2}{*}{ Komoditas } & \multirow{2}{*}{$\begin{array}{c}\text { WPP } \\
572 \\
\text { Tahun } \\
2016 \\
\end{array}$} & \multicolumn{2}{|c|}{ Tahun 2014} & \multicolumn{2}{|c|}{ Tahun 2015} & \multicolumn{2}{|c|}{ Tahun 2016} & \multicolumn{2}{|c|}{ Tahun 2017} & \multicolumn{2}{|c|}{ Tahun 2018} \\
\hline & & Prod. & $(\%)$ & Prod. & $(\%)$ & Prod. & $(\%)$ & Prod. & $(\%)$ & Prod. & $(\%)$ \\
\hline Cakalang & 30.736 & 9.641 & 31,37 & $10.981,33$ & 35,73 & $8.474,62$ & 27,57 & $13.709,37$ & 44,60 & $15.352,39$ & 49,95 \\
\hline Madidihang & 11.881 & 1.799 & 15,14 & $3.573,31$ & 30,08 & $1.872,64$ & 15,76 & $2.231,42$ & 18,78 & $2.524,52$ & 21,25 \\
\hline $\begin{array}{l}\text { Tongkol } \\
\text { Komo }\end{array}$ & 16.695 & 1.201 & 7,19 & 540,71 & 3,24 & 177,15 & 1,06 & 127,56 & 0,76 & 40,4 & 0,24 \\
\hline Tongkol krai & 37.380 & 3.020 & 8,08 & $3.581,73$ & 95,82 & $2.140,54$ & 5,73 & 953,3 & 2,55 & $1.956,6$ & 5,23 \\
\hline
\end{tabular}

Sumber: Data Statistik PPN Sibolga (dalam ton)

Tabel 2. Kontribusi produksi TCT per spesies yang didaratkan di PPN Sibolga terhadap total produksi TCT Nasional 2016

Table 2. Contribution of TCT production per species landed at PPN Sibolga to the total production of National TCT 2016

\begin{tabular}{|c|c|c|c|c|c|c|c|c|c|c|c|}
\hline \multirow{2}{*}{ Komoditas } & \multirow{2}{*}{$\begin{array}{c}\text { Produksi } \\
\text { nasional } \\
\text { Tahun } \\
2016 \\
\text { (Ton) } \\
\end{array}$} & \multicolumn{2}{|c|}{ Tahun 2014} & \multicolumn{2}{|c|}{ Tahun 2015} & \multicolumn{2}{|c|}{ Tahun 2016} & \multicolumn{2}{|c|}{ Tahun 2017} & \multicolumn{2}{|c|}{ Tahun 2018} \\
\hline & & Prod. & $(\%)$ & Prod. & $(\%)$ & Prod. & $(\%)$ & Prod. & $(\%)$ & Prod. & $(\%)$ \\
\hline Cakalang & 440.812 & 9.641 & 2,19 & $10.981,33$ & 2,49 & $8.47, .62$ & 1,92 & $13.709,37$ & 3,11 & $15.352,39$ & 3,48 \\
\hline Madidihang & 209.227 & 1.799 & 0,86 & $3.573,31$ & 1,71 & $1.872,64$ & 0,90 & $2.231,42$ & 1,07 & $25.24,52$ & 1,21 \\
\hline $\begin{array}{l}\text { Tongkol } \\
\text { Komo }\end{array}$ & 190.566 & 1.201 & 0,63 & 540,71 & 0,28 & 177,15 & 0,09 & 127,56 & 0,07 & 40,4 & 0,02 \\
\hline $\begin{array}{l}\text { Tongkol } \\
\text { krai }\end{array}$ & 184.586 & 302 & 0,16 & $3.581,73$ & 1,94 & $2.140,54$ & 1,16 & 953,3 & 0,52 & $1.956,6$ & 1,06 \\
\hline
\end{tabular}

Sumber: Data Statistik PPN Sibolga

Tabel 3. Produksi TCT yang didaratkan di PPN Sibolga $(\mathrm{Kg})$

Table 3. Production of TCT landed at PPN Sibolga (Kg)

\begin{tabular}{lcccccccc}
\hline \multicolumn{1}{c}{ Wilayah } & FRI & ALB & BLT & KAW & LOT & SKJ & YFT & Total \\
\hline Laut Lepas & 46.000 & & 400 & 500 & 13.300 & 1.166 .440 & 206.100 & 1.432 .740 \\
Teritorial & 389.092 & 4444 & 7.453 & 188.343 & 24.310 & 711.701 & 88.839 & 1.414 .882 \\
Zee & 384.899 & 48.600 & 11.800 & 459.310 & 61.981 & 8.316 .265 & 1.302 .792 & 10.585 .747 \\
\hline Total & $\mathbf{8 1 9 . 9 9 1}$ & $\mathbf{5 3 . 0 4 4}$ & $\mathbf{1 9 . 6 5 3}$ & $\mathbf{6 4 8 . 1 5 3}$ & $\mathbf{9 9 . 5 9 1}$ & $\mathbf{1 0 . 1 9 4 . 4 0 6}$ & $\mathbf{1 . 5 9 7 . 7 3 1}$ & $\mathbf{1 3 . 4 3 3 . 3 6 9}$ \\
\hline
\end{tabular}

Sumber: Logbook Sibolga 


\section{e. Produksi Per Alat Tangkap}

Produksi TCT di WPP RI 572 di PPS Sibolga pada tahun 2018 menurut logbook tahun 2018, alat tangkapyang mendominasi adalah purse seine dengan hasil tangkapan TCT sebanyak 13.021,829 ton. Total tangkapan keseluruhan mencapai 13.433,369 ton. Produksi TCT pada alat tangkap bagan mencapai 187,645 ton, sedangkan produksi pancing ulur 223,896 ton. (Tabel 4). Pengelolaan perikanan melalui pengelolaan sumberdaya ikan berbasis WPP perlu dilakukan unutk menghasilkan perikanan tangkap yang berkelanjutan (Kusdiantoro et al., 2019). Selain itu juga untuk menjaga tingkat pemanfaatannya supaya tidak lebih tangkap (Zedta \& Setyadji, 2020). Kontribusi TCT di Sumatera Utara cukup besar dalam skala WPP 572 untuk ikan cakalang, namun tidak berpengaruh besar pada skala nasional. Peningkatan yang terjadi setiap tahunnya sudah di ramalkan sebelumya akan perkembangan produksi TCT tahun 2012-2018 mengalami peningkatan setiap tahunnya dengan ratarata mencapai $17 \%$ (Kurnia \& Lubis, 2019).

\section{f. Sebaran daerah dan Hasil tangkapan per Alat Tangkap}

Sebaran produksi pada alat tangkap ini terdapat dari wilayah teritorial, ZEE, hingga laut lepas. Pada skala sebara peta $1 \times 1$. Alat tangkap pukat cincin sebaran terbesar mencapai 2500 ton yang terdapat pada zona ZEE pada koordinat $3^{\circ} \mathrm{LU}-2^{\circ} \mathrm{LU}$ dan $95^{\circ}$ BT - $96^{\circ}$ BT. Sebaran daerah penangkapan alat tangkap ini dari $6^{\circ} \mathrm{LU}-6^{\circ} \mathrm{LS}$ dan $85^{\circ} \mathrm{BT}-101^{\circ} \mathrm{BT}$. Alat tangkap pancing ulur sebaran terbesar mencapai 160 ton yang terdapat pada perbatasan antara zona ZEE dan teritorial pada koordinat $1^{\circ} \mathrm{LU}-0^{\circ} \mathrm{LS}$ dan $97^{\circ}$ BT - $98^{\circ}$ BT. Sebaran daerah penangkapan alat tangkap ini dari $4^{\circ} \mathrm{LU}-2^{\circ} \mathrm{LS}$ dan $92^{\circ} \mathrm{BT}$ - $99^{\circ} \mathrm{BT}$. Alat tangkap bagan sebaran terbesar mencapai 120 ton yang terdapat pada perbatasan di wilayah teritorial pada koordinat $2^{\circ} \mathrm{LU}-1^{\circ} \mathrm{LU}$ dan $96^{\circ} \mathrm{BT}-97^{\circ} \mathrm{BT}$. Sebaran daerah penangkapan alat tangkap ini dari $3^{\circ} \mathrm{LU}-2^{\circ}$ LS dan $98^{\circ}$ BT - $99^{\circ}$ BT. (Gambar 4)

Tabel 4. Produksi TCT yang didaratkan di PPN Sibolga berdasarkan alat tangkap

Table 4. Production of TCT landed at PPN Sibolga by fishing gear

\begin{tabular}{|c|c|c|c|c|c|c|c|c|}
\hline $\begin{array}{l}\text { Alat } \\
\text { Tangkap }\end{array}$ & FRI & ALB & BLT & KAW & LOT & SKJ & YFT & Total \\
\hline Bagan & 107.632 & & 1.000 & 66.103 & 5.960 & & 6.450 & 187.645 \\
\hline Pancing Ulur & 4.400 & 2.344 & & & & 179.301 & 37.851 & 223.896 \\
\hline Purse Seine & 707.959 & 50.700 & 18.653 & 582.050 & 93.631 & 1.015 .105 & 1.553 .430 & 13.021 .828 \\
\hline Grand Total & 819.991 & 53.044 & 19.653 & 648.153 & 99.591 & 10.194 .406 & 1.597 .731 & 13.433.369 \\
\hline
\end{tabular}

Ket: dalam $\mathrm{Kg}$

Sumber: Logbook Sibolga

\section{g. Sebaran daerah dan Hasil tangkapan per spesies}

\section{Tuna Sirip kuning}

Pada alat pukat cincin sebaran hasil tangkapan tuna sirip kuning WPP RI 572 di PPS Sibolga sangat luas. Sebaran tuna sirip kuning mencapai 250 ton pada lintang $2^{\circ} \mathrm{LS}-3^{\circ} \mathrm{LS}$ dan $95^{\circ} \mathrm{BT}-96^{\circ}$ BT. Sebaran terendah adalah 50 ton yang hampir merata di seluruh daerah. Alat tangkap pancing ulur menunjukan adanya hasil tangkapan yang hampir merata diseluruh wilayah dimana tuna sirip kuning tertangkap. Alat tangkap ini lebih dominan digunakan untuk daerah pengoperasian di wilayah territorial dan ZEE. alat tangkap bagan sangat tidak efektif atau kemungkina tertangkap tanpa sengaja. Sebaran tuna sirip kuning hanya terdapat pada satu titik antara lintang $3^{\circ} \mathrm{LS}-2^{\circ} \mathrm{LS}$ dan $96^{\circ} \mathrm{BT}-97^{\circ} \mathrm{BT}$. (Gambar $5)$.

\section{Albakora}

Hasil Produksi menunjukan adanya kesamaan dari semua titik tertangkap dengan sebaran sampai dengan
50 ton setiap skala $1 \times 1$ pada peta. Untuk mengetahui lebih jelas, dapat dilihat pada Gambar 6 .

\section{Cakalang}

Pada alat pukat cincin sebaran hasil tangkapan tuna sirip kuning WPP RI 572 di PPS sebaran cakalang mencapai 2000 ton pada lintang $3^{\circ} \mathrm{LS}-2^{\circ} \mathrm{LS}$ dan $95^{\circ}$ BT - $96^{\circ}$ BT. Alat tangkap ini lebih dominan digunakan untuk daerah pengoperasian di wilayah territorial dan ZEE. Alat tangkap ini menghasilkan cakalang yang tidak terlalu maksimal pada spesies ini. Sebaran cakalang mencapai 125 ton pada lintang $1^{\circ} \mathrm{LS}-0^{\circ} \mathrm{LS}$ dan $97^{\circ}$ BT - $98^{\circ}$ BT. (Gambar 7).

\section{Tongkol Krai}

Pada alat tangkap pukat cincin hasil produksi menunjukan adanya kesamaan dari semua titik tertangkap dengan sebaran sampai dengan 50 ton setiap skala $1 \times 1$ pada peta. Sebaran tongkol mencapai 200 ton pada lintang $3^{\circ} \mathrm{LU}-2^{\circ} \mathrm{LU}$ dan $95^{\circ}$ BT $-97^{\circ}$ BT. pada alat tangkap pancing ulur menunjukan adanya hasil tangkapan yang hanya berada 
pada $2^{\circ} \mathrm{LU}-0^{\circ} \mathrm{LU}$ dan $96^{\circ} \mathrm{BT}-98^{\circ} \mathrm{BT}$. Tongkol Krai yang tertangkap mencapai sebaran 50 ton. Alat tangkap bagan menunjukan adanya hasil tangkapan yang hampir merata terutama wilayah perbatasan territorial dan
ZEE. Sebaran hasil tangkpan pada alat tangkap ini berada pada $3^{\circ} \mathrm{LU}$ - $2^{\circ} \mathrm{LS}$ dan $95^{\circ} \mathrm{BT}$ - $99^{\circ} \mathrm{BT}$. Tongkol Krai yang tertangkap mencapai sebaran 60 ton pada $2^{\circ} \mathrm{LU}-1^{\circ} \mathrm{LS}$ dan $98^{\circ} \mathrm{BT}-99^{\circ}$ BT (Gambar 8).

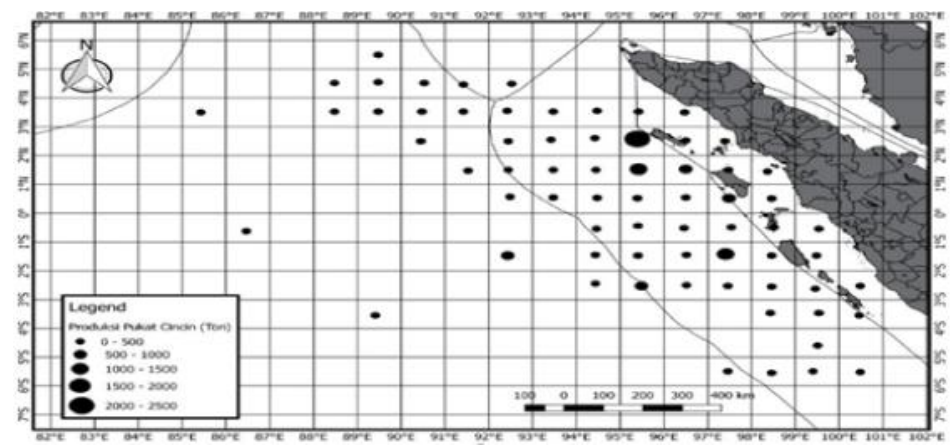

(a)

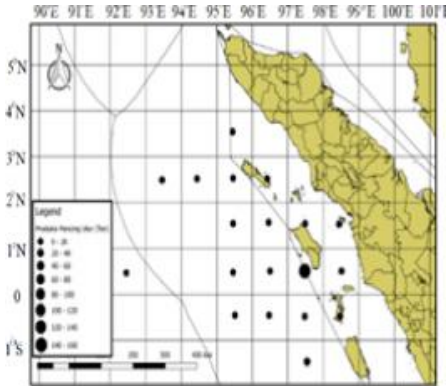

(b)

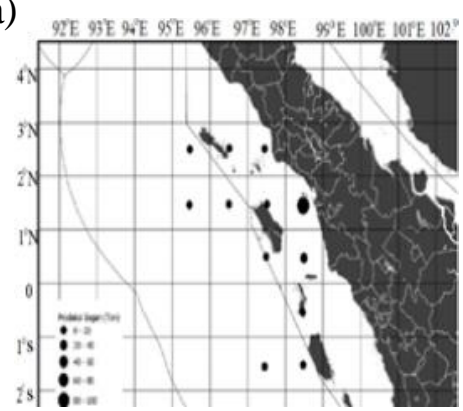

(c)

Sumber: Logbook Sibolga

Gambar 4. Produksi TCT (a) pukat cincin (b) pancing ulur (c) bagan.

Figure 4. TCT production (a) purse seine (b) hand line (c) Boat/Raft Lift Net.

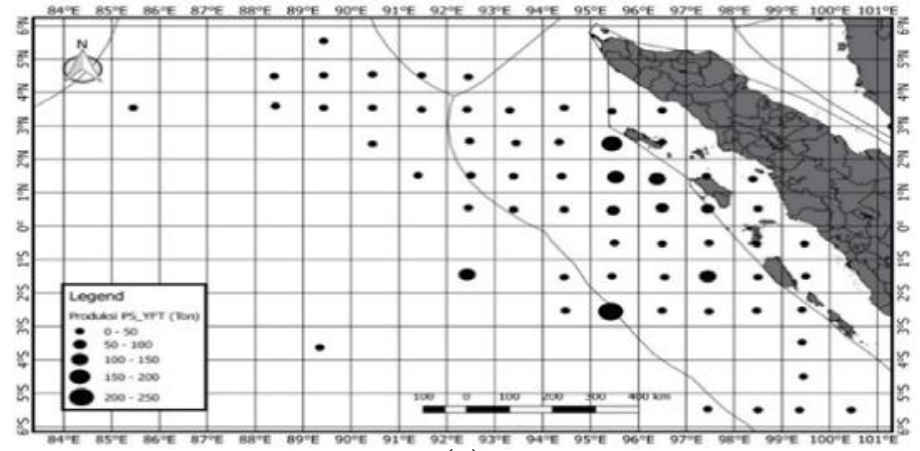

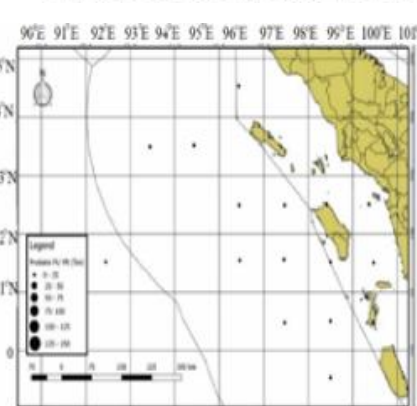

(b) (a) $\quad 95^{\circ} \mathrm{E} \quad 96 \mathrm{E} \quad 97 \mathrm{E} \quad 98^{\circ} \mathrm{E} \quad 99^{\circ} \mathrm{E} \quad 100 \mathrm{E}$

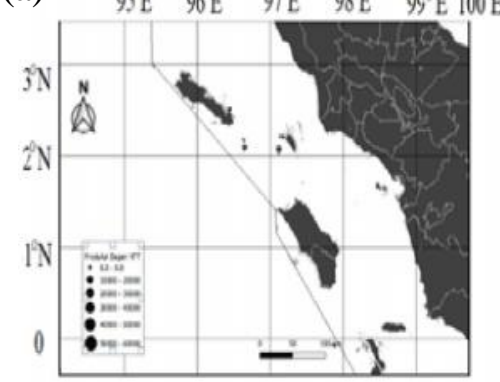

(c)

Sumber: Logbook Sibolga

Gambar 5. Sebaran Produksi tuna sirip kuning yang tertangkap oleh yang tertangkap oleh (a) alat tangkap pukat cincinalat (b) tangkap pancing ulur (c) alat tangkap bagan.

Figure 5. Production distribution of yellowfin tuna caught by those caught by (a) cincinalat trawl fishing gear (b) hand-line fishing (c) Boat/Raft Lift Net. 


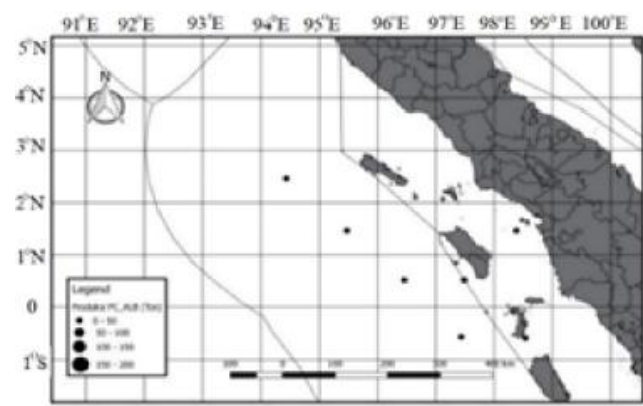

(a)

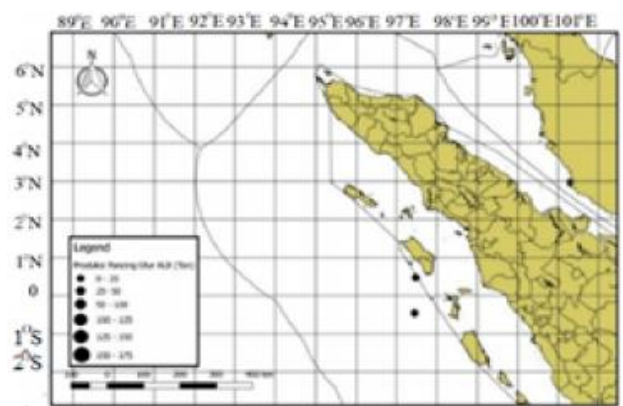

(b)

Sumber: Logbook Sibolga

Gambar 6. Produksi Albakora (a) pukat cincin (b) pancing ulur.

Figure 6. Albacore Production (a) purse seines (b) hand-line fishing gear.

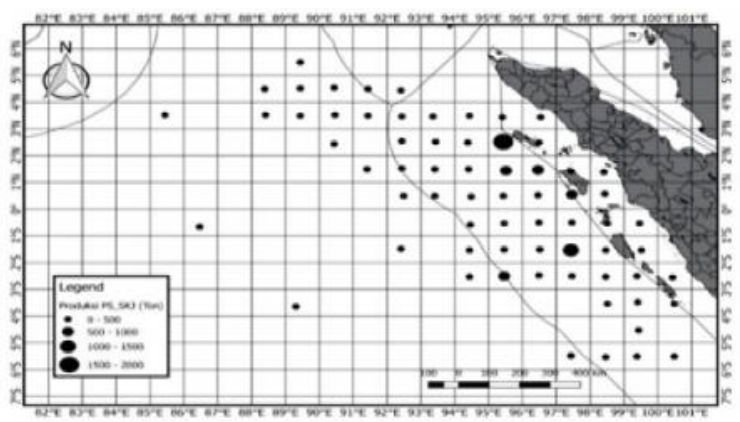

(a)

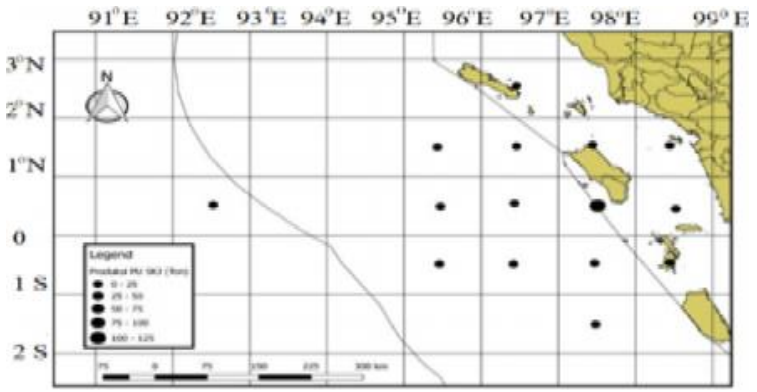

(b) Sumber: Logbook Sibolga

Gambar 7. Produksi Cakalang (a) pukat cincin (b) pancing ulur.

Figure 7. Skipjack tuna production (a) purse seine (b) hand line.

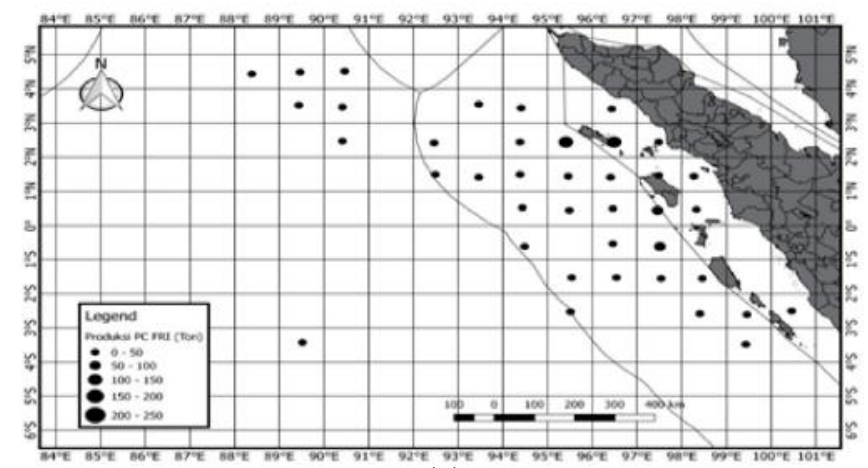

(a)

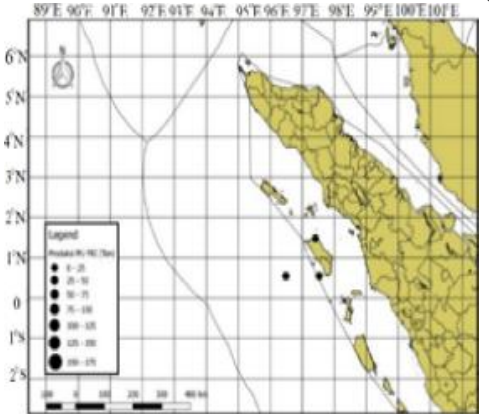

(b)

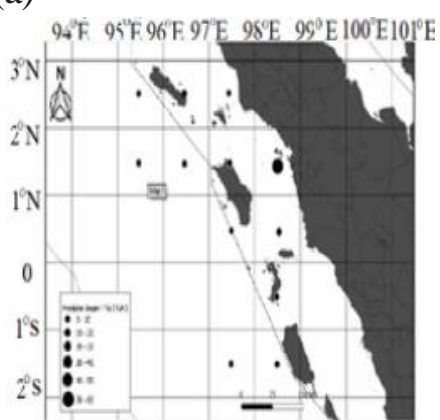

(c)

Sumber: Logbook Sibolga

Gambar 8. Produksi Tongkol Krai (a pukat cincin (b) pancing ulur (c) bagan.

Figure 8. Krai Cob production (a) purse seine (b) hand-line (c) Boat/Raft Lift Net. 


\section{Tongkol Kawa-Kawa}

Hasil Produksi menunjukan adanya kesamaan dari semua titik tertangkap dengan sebaran sampai dengan 50 ton setiap skala $1 \times 1$ pada peta.

\section{Tongkol Lisong}

Hasil Produksi menunjukan adanya kesamaan dari semua titik tertangkap dengan sebaran sampai dengan 50 ton setiap skala $1 \times 1$ pada peta.

Sebaran daerah penangkapan secara garis besar penangkpan dilakukan di wilayah ZEE dan territorial. Alat tangkap yang digunakan di Sumatera Utara masih mengandalkan rumpon sebagai alat bantu penagkpannya, sehingga sebaran daerah penangkapan masih sebagaian besar berada di wilayah ZEE. Sedangkan daerah penangkapan yang berasal yang berasal dari Benoa di luar ZEE, karena alat tangkap utama yang berbeda yaitu longline (Wudianto, Wagiyo and Wibowo, 2003). Sedangkan pada WPP 573 penangkapan TCT tertinggi pada koordinat antara $8^{\circ}$ $-10^{\circ} \mathrm{LS}$ dan $107^{\circ}-110^{\circ} \mathrm{BT}$ dimana area tersebut masih berada di dalam wilayah ZEE (Nugroho and Jatmiko, 2019). Sehingga pengaruh alat tangkap dan armada juga menjadi sesuatu hal yang mempengaruhi produktivitas dan hasil tangkapan. Peraturan tentang penggunaan dan izin operasional daerah pennagkapan perlu dilakukan evaluasi setiap saat dengan pemetaan produksi sebaran hasil tangkapan, agar tidak terjadi lebih tangkap.

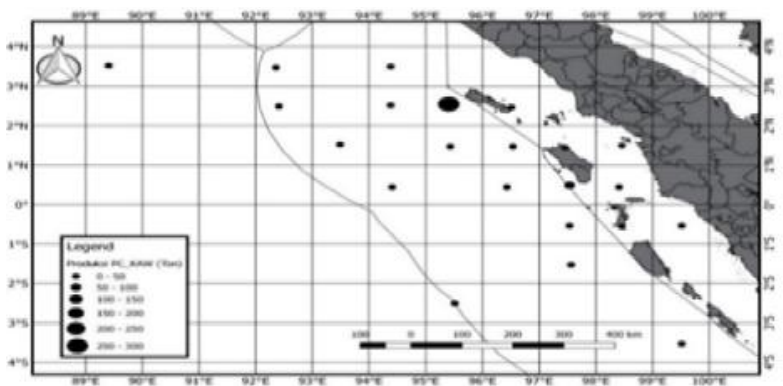

(a)

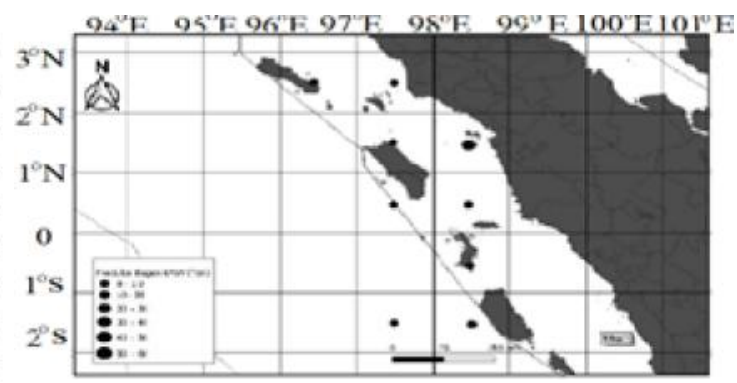

(b)

Sumber: Logbook Sibolga

Gambar 9. Produksi Tongkol Kawa-Kawa (a) pukat cincin (b) bagan.

Figure 9. Kawa-Kawa tuna (a) purse seine (b) Boat/Raft Lift Net.

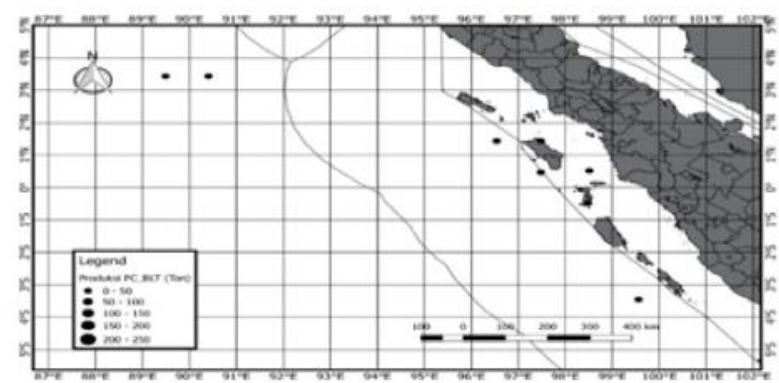

(a)

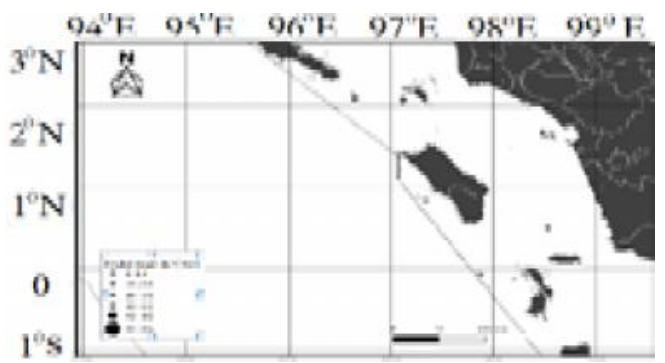

(b)

Sumber: Logbook Sibolga

Gambar 10. Produksi Tongkol Lisong (a) pukat cincin (b) bagan.

Figure 10. Lisong Cob Production (a) purse seine (b) Boat/Raft Lift Net.

\section{KESIMPULAN}

Laju tangkap TCT mengalami kenaikan dari tahun 2014 hinga tahun 2018. Hasil produksi TCT lebih banyak didaratkan di tangkahan dari pada di Pelabuhan Perikanan.Kontribusi TCT di Sumatera utara tertinggi cakalang, terendah Tongkol Komo. Kontribusi TCT Terhadap WPP 572 besar akan tetapi terhadap nasional sedikitHasil tangkapan TCT di lebih banyak tertangkap di ZEE, dan Teritorial dari pada di laut lepas.

\section{UCAPAN TERIMA KASIH}

Terima kasih kepada Loka Riset Perikanan Tuna, penelitian ini merupakan bagian dari kegiatan Loka Riset Perikanan Tuna TA. 2019. PPN Terima kasun unutk PPN Sibolga, Dinas Provinsi Sumatera Utara, Dinas Tapanuli Tengah, Selatan, dan Kota Sibolga. Seluruh pihak yang terlibat. 


\section{DAFTAR PUSTAKA}

Agustina, M., Jatmiko, I. and Sulistyaningsih, R. K. (2020) 'Komposisi Hasil Tangkapan Dan Daerah Penangkapan Pancing Ulur Tuna Di Perairan Sendang Biru', Jurnal Pendidikan Geografi Undiksha, 25(4), pp. 241-251. Available at: Daerah penangkapan ikan; komposisi hasil tangkapan; pancing ulur; Sendang Biru.

Arnenda, G. L. and Rochman, F. (2019) 'Sebaran Daerah Penangkapan Dan Potensi Stok Sumber Daya Ikan Tuna Tongkol Cakalang Di Labuhan Lombok', in Istiqomah, In. and Satriyo, T. Bu. (eds) Seminar Nasional Tahunan XVI Hasil Penelitian Perikanan dan Kelautan Tahun 2019. Yogyakarta: Departemen Perikanan, Fakutas Pertanian UGM, pp. 274-282. Available at: http://prosiding.semnaskan-ugm.org/ index.php/psu/issue/view/prosiding-semnaskanugm-xvi-2019.

Atmaja, S. B., Natsir, M. and Sadhotomo, B. (2012) 'Dinamika Spasial Perikanan Pukat Cincin Di Laut Jawa Dan Samudera Hindia', Jurnal Penelitian Perikanan Indonesia, 18(2), pp. 69-76. Available at: http://ejournal-balitbang.kkp.go.id/index.php/ jppi/article/view/987/922.

Firdaus, M. (2019) 'Profil Perikanan Tuna Dan Cakalang Di Indonesia', Buletin IImiah Marina Sosial Ekonomi Kelautan dan Perikanan, (021), pp. 2332. Available at: http://ejournal-balitbang.kkp.go.id/ index.php/mra/article/view/7328.

Hidayat, T., Noegroho, T. and Wagiyo, K. (2017) 'Struktur Ukuran Dan Beberapa Parameter Populasi Ikan Cakalang ( Katsuwonus Pelamis Linnaeus , 1758 ) Di Samudera Pasifik Utara Papua', BAWAL, 9(2), pp. 113-121. Available at: http://ejournalbalitbang.kkp.go.id/index.php/bawal/article/view/ 3553/5294.

IOTC (2018) Report of the 22nd Session of the Indian Ocean Tuna Commission. IOTC-2018-. Bangkok,Thailand.

IOTC (2019) 'Report of the 22 nd Session of the IOTC Scientific Committee', (December), pp. 2-6. Available at: https://iotc.org/documents/WPTT/21/ RE.

Jatmiko, I., Catur, S. and Fahmi, Z. (2020) 'Karakteristik Perikanan Pukat Cincin Pelagis Besar Di Perairan Samudra Hindia (Wppnri 572 Dan 573)', Jurnalpenelitianperikananindonesia, 26, pp.37-46. Available at: http://ejournal-balitbang.kkp.go.id/ index.php/bawal/article/view/294/300.

Kurnia and Lubis, E. (2019) 'Samudera Kutaraja Provinsi Aceh Projection Of Fish Catch Production Projection In Ocean', Jurnal Teknologi Perikanan dan Kelautan, 10(1), pp. 69-77. Available at: http://journal.ipb.ac.id/index.php/jtpk/article/ view/27971/19000.

Kusdiantoro et al. (2019) 'Perikanan Tangkap Di Indonesia/ : Potret Dan Tantangan Keberlanjutannya', JUrnal Sosi, 14(2), pp. 145-162. Available at: http://ejournal-balitbang.kkp.go.id/ index.php/sosek/article/view/8056/6458.

Limbong, I. (2019) 'Produktivitas Alat Tangkap Pukat Cincin Di Pelabuhan Perikanan Nusantara Sibolga Provinsi Sumatera Utara', JURNAL PERIKANAN DAN KELAUTAN, 24(2), pp. 78-83. Available at: http://journal.ipb.ac.id/index.php/jpsp/article/view/ 13328.

Nugroho, S. C. and Jatmiko, I. (2019) 'Produksi Dan Komposisi Tuna Cakalang Dan Tongkol (Tct) Di Wilayah Zona Ekonomi Eksklusif (Zee) Dan Laut Lepas Di Samudra Hindia Selatan Jawa', in Istiqomah, I. and Budi, satriyo. T. (eds) Seminar Nasional Tahunan XVI Hasil Penelitian Perikanan dan Kelautan Tahun 2019 PRODUKSI. Yogyakarta: Departemen Perikanan, Fakutas Pertanian UGM, pp. 266-273. Available at: http:// prosiding.semnaskan-ugm.org/index.php/psu/ issue/view/prosiding-semnaskan-ugm-xvi-2019.

Salmarika, Tauruman, A. A. and Wisudo, H. S. (2019) 'Status Pengelolaan Sumber Daya Ikan Tongkol Di Perairan Samudera Hindia Berbasis Pendaratan Pukat Cincin Di Pelabuhan Perikanan Samudera Lampulo, Aceh: Suatu Pendekatan Ekosistem', $B A W A L, 24(4)$, pp. 263-272. Available at: http:// ejournal-balitbang.kkp.go.id/index.php/jppi/article/ view/7417/6135.

Simatupang, S. M. and Lubis, E. (2012) 'Pengaruh Keberadaan Tangkahan Terhadap Pendaratan Hasil Tangkapan Pelabuhan Perikanan Nusantara Sibolga', Marine Fisheries, 3(1), pp. 23-33. Available at: http:/journal.ipb.ac.id/index.php/jpsp/article/view/ 13328.

Sulistyaningsih, R. K., Barata, A. and Siregar, K. (2011) 'Perikanan Pancing Ulur Tuna Di Kedonganan, Bali', Jurnal Penelitian Perikanan Indonesia, 17(3), pp. 185-191. Available at: http://ejournalbalitbang.kkp.go.id/index.php/jppi/article/view/ $3373 / 2891$.

Tangke, U. (2014) 'Pendugaan Daerah Penangkapan Ikan Pelagis Berdasarkan Pendekatan Suhu Permukaan Laut Dan Klorofil-A Di Laut Maluku', Jurnal Agribisnis Perikanan, 7(1), pp. 74-81. Available at: https://ejournal.stipwunaraha.ac.id/ index.php/AGRIKAN/article/view/95.

Wijopriyono (2012) 'Daya Dukung Sumber Daya Perikanan Tuna Di Samudera Hindia Dalam Kaitannya Dengan Industrialisasi Perikanan', JUrnal Kebijakan Periknaan Indonesia, 4(2), pp. 101-108. Wudianto, Wagiyo, K. and Wibowo, B. (2003) 'Sebaran 
Daerah Penangkapan Ikan Tuna Di Samudera Hindia', Jurnal Penelitian Perikanan Indonesia, 9(7), pp. 19-28. Available at: http://ejournalbalitbang.kkp.go.id/index.php/jppi/article/view/ $4687 / 4087$.

Wurlianty, H. A., Wenno, J. and Kayadoe, M. E. (2015) 'Catch per unit effort ( CPUE ) periode lima tahunan perikanan pukat cincin di Kota Manado dan Kota
Bitung', Jurnal IImu dan Teknologi Perikanan Tangkap, 2(1), pp. 1-8. Available at: https:// ejournal.unsrat.ac.id/index.php/JITPT/article/view/ 8292/7851.

Zedta, R. R. and Setyadji, B. (2020) 'Optimalisasi Pcr Ikan Tongkol Krai ( Auxis Thazard ) Dan Lisong ( Auxis Rochei ) Pada Analisis Keragaman Genetik', BAWAL, 11(2), pp. 95-102. 